\title{
PEP-1-paraoxonase 1 fusion protein prevents cytokine-induced cell destruction and impaired insulin secretion in rat insulinoma cells
}

\author{
Su Jin Lee ${ }^{1}$, Hyung Kyung Kang ${ }^{2}$, Yeon Joo Choi ${ }^{3}$, Won Sik Eum ${ }^{3}$, Jinseu Park ${ }^{3}$, Soo Young Choi ${ }^{3, *}$ E Hyeok Yil Kwon ${ }^{1, *}$ \\ ${ }^{1}$ Department of Physiology, College of Medicine, Hallym University, Chuncheon 24252, ${ }^{2}$ Department of Physiology, College of Medicine, \\ Korea University, Seoul 02841, ${ }^{3}$ Department of Biomedical Science and Research Institute of Bioscience and Biotechnology, Hallym \\ University, Chuncheon 24252, Korea
}

\begin{abstract}
Pancreatic beta cell destruction and dysfunction induced by cytokines is a major cause of type 1 diabetes. Paraoxonase 1 (PON1), an arylesterase with antioxidant activity, has been shown to play an important role in preventing the development of diabetes in transgenic mice. However, no studies have examined the anti-diabetic effect of PON1 delivered to beta cells using protein transduction. In this study, we expressed the cell-permeable PON1 fused with PEP-1 protein transduction domain (PEP-1-PON1) to investigate whether transduced PEP-1-PON1 protects beta cells against cytokine-induced cytotoxicity. PEP-1-PON1 was effectively delivered to INS-1 cells and prevented cytokine-induced cell destruction in a dose-dependent manner. Transduced PEP-1-PON1 significantly reduced the levels of reactive oxygen species (ROS) and nitric oxide (NO), DNA fragmentation, and expression of inflammatory mediators, endoplasmic reticulum (ER) stress proteins, and apoptosis-related proteins in cytokine-treated cells. Moreover, transduced PEP-1-PON1 restored the decrease in basal and glucose-stimulated insulin secretion induced by cytokines. These data indicate that PEP-1-PON1 protects beta cells from cytokine-induced cytotoxicity by alleviating oxidative/nitrosative stress, ER stress, and inflammation. Thus, PEP-1-mediated PON1 transduction might be an effective method to reduce the extent of destruction and dysfunction of pancreatic beta cells in autoimmune diabetes. [BMB Reports 2018; 51(10): 538-543]
\end{abstract}

*Corresponding authors. Hyeok Yil Kwon, Tel: +82-33-248-2584; Fax: +82-33-248-2580; E-mail: hykwon@hallym.ac.kr; Soo Young Choi, Tel: +82-33-248-2112; Fax: +82-33-256-3420; E-mail: sychoi@ hallym.ac.kr

https://doi.org/10.5483/BMBRep.2018.51.10.181

Received 3 August 2018, Revised 24 August 2018, Accepted 10 September 2018

Keywords: Beta cell destruction, Cytokines, Diabetes, Insulin secretion, PEP-1-PON1

\section{INTRODUCTION}

Type 1 diabetes results from the progressive destruction of beta cells induced by the cytokines released by infiltrated macrophages and $\mathrm{T}$ cells in the pancreas. Proinflammatory cytokines, in particular, interleukin-1 $\beta$ (IL-1 $\beta$ ) in combination with tumor necrosis factor- $\alpha$ (TNF- $\alpha$ ) and interferon- $\gamma$ (IFN- $\gamma$ ), play a crucial role in the elimination of beta cells (1). Proinflammatory cytokines are known to induce apoptotic cell death through overproduction of ROS and NO by beta cells (2-4). In addition, excessive reduction in the number of beta cells with progressing diabetes results in insulin insufficiency and contributes to the development of hyperglycemia, which has been shown to directly induce oxidative stress through several mechanisms, including glycation, autoxidation, and NADH production $(5,6)$. Thus, oxidative stress plays a crucial role as a mediator of beta cell destruction in autoimmune diabetes.

Paraoxonases (PONs) are a family of mammalian enzymes that can hydrolyze toxic organophosphate compounds such as paraoxon and some fatally toxic nerve agents. Among them, PON1 is the most studied member because it has various characteristics such as antioxidant, anti-atherogenic, antiinflammatory, and anti-diabetic activities in addition to the hydrolyzing effect exerted on organophosphate compounds ( 7 , 8). PON1 associated with high-density lipoproteins in the blood prevents atherosclerosis by hydrolyzing atherogenic compounds, including oxidized low-density lipoproteins, phospholipid peroxidation adducts, and homocysteine thiolactones. Recent studies have also shown that PON1 has anti-diabetic activity. Increased PON1 activity by overexpression suppressed the onset of diabetes in PON1 transgenic mice, whereas depletion of PON1 activity enhanced insulin resistance by increasing oxidative stress in PON1 knockout mice $(9,10)$. In addition, decreased plasma PON1 activity has been reported in diabetic patients with hyperglycemia (11). Thus, PON1 might play a beneficial role in the development of oxidative stress-associated diabetes as well as in the prevention of atherosclerosis.

ISSN: 1976-670X (electronic edition)

Copyright (C) 2018 by the The Korean Society for Biochemistry and Molecular Biology

(c) This is an open-access article distributed under the terms of the Creative Commons Attribution Non-Commercial License (http://creativecommons.org/licenses/by-nc/4.0) which permits unrestricted non-commercial use, distribution, and reproduction in any medium, provided the original work is properly cited. 
Several studies have discussed the rationale underlying increased antioxidant capacity in beta cells to enhance their resistance against the cytotoxic challenge exerted by oxidative stress. Overexpression of antioxidant enzymes increases the resistance of beta cells against cytokine-induced cytotoxicity through inactivation of ROS (12). On the other hand, protein transduction technology using protein transduction domains (PTDs) has also been shown to be an effective tool for direct delivery of antioxidant enzymes to beta cells $(13,14)$. PTD, a cell-penetrating peptide derived from viruses such as PEP-1, Tat, and VP22, has been shown to facilitate the direct delivery of large biomolecules into cells without mediating specific transporters or receptors. In previous studies, we showed that increased ROS-scavenging activity by PTD-mediated transduction of antioxidant enzymes enhanced the resistance of beta cells to the cytotoxicity induced by ROS, NO, and islet amyloid polypeptide $(13,15)$.

In this study, PEP-1-mediated PON1 transduction was performed in INS-1 cells to investigate whether the transduced PEP-1-PON1 protects beta cells against cytokine-induced cytotoxicity. We found that PEP-1-PON1 was efficiently transduced into INS-1 cells through a membrane barrier, and that the transduced PEP-1-PON1 reduced cytokine-induced

A

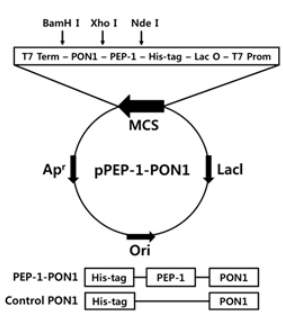

B

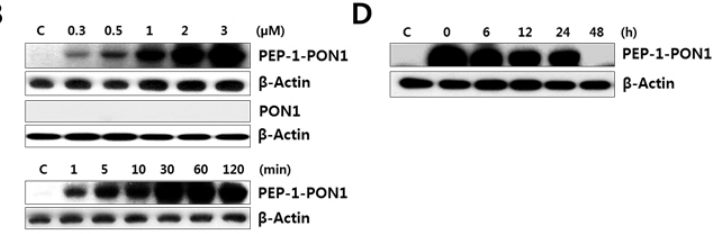

Fig. 1. Schematic diagram of PEP-1-PON1 expression vector based on the vector $p E T-15 b$ and the expressed PEP-1-PON1 fusion protein (A). Transduction of PEP-1-PON1 into INS-1 cells (B). For dose-dependent transduction, different concentrations $(0.3-3 \mu \mathrm{M})$ of PEP-1-PON1 and control PON1 were added to the culture medium for $1 \mathrm{~h}$. For time-dependent transduction, $2 \mu \mathrm{M}$ PEP-1-PON1 was added to the culture medium for 1-120 min. After incubation, the level of transduced protein was determined by western blotting. Immunofluorescence analysis of the transduced PEP-1-PON1 (C). INS-1 cells treated with $2 \mu \mathrm{M}$ PEP-1-PON1 or control PON1 were fixed with paraformaldehyde, treated with anti-His-tag primary antibody, and incubated with fluoresceinconjugated secondary antibody. Scale bar, $25 \mu \mathrm{m}$. Intracellular stability of the transduced PEP-1-PON1 (D). INS-1 cells pretreated with $2 \mu \mathrm{M}$ PEP-1-PON1 for $1 \mathrm{~h}$ were washed with fresh culture medium and further cultured for 6-48 $\mathrm{h}$. cell destruction and impaired insulin secretion.

\section{RESULTS AND DISCUSSION}

\section{Transduction of PEP-1-PON1 into INS-1 cells}

ROS is a crucial mediator of cytokine-induced beta cell destruction in autoimmune diabetes, and beta cells are, in particular, susceptible to the deleterious effects of ROS because of the low expression of antioxidant enzymes in the pancreas $(2,16)$. In this study, an antioxidant enzyme PON1 fused with PEP-1 was expressed to determine whether the increase of PON1 activity by protein transduction has cytoprotective effect on cytokine-exposed beta cells. To evaluate the transduction ability of purified PEP-1-PON1 across cell membranes, cells were incubated with various concentrations $(0.3-3 \mu \mathrm{M})$ of PEP-1-PON1 for various time intervals (1-120 min). As shown in Fig. 1B, PEP-1-PON1 was successfully transduced into the INS- 1 cells in a dose- and time-dependent manner. PEP-1-PON1 proteins were detectable within $1 \mathrm{~min}$ of treatment, and the intracellular PEP-1-PON1 levels were at the peak within 30-60 min of treatment. In contrast, the control PON1 protein lacking the PEP-1 domain was not delivered into the cells. Transduction of
A

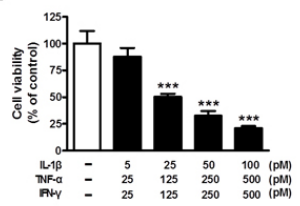

C

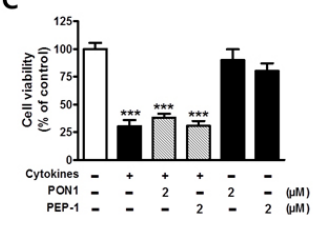

B

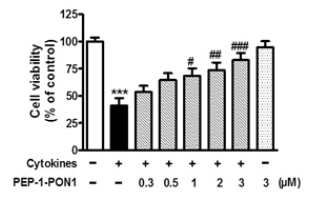

D

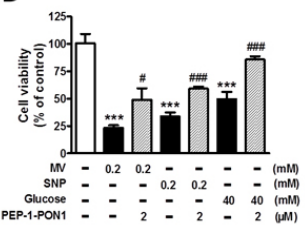

Fig. 2. Effect of cytokines on cell viability of INS-1 cells (A). Cells were treated with various combinations of cytokines for 24 $h$, and cell viability was determined by MTT assay. Effect of transduced PEP-1-PON1 on the cell viability of INS-1 cells treated with cytokines (B). Cells pretreated with 0.3-3 $\mu \mathrm{M}$ PEP-1-PON1 were incubated with a combination of cytokines for $24 \mathrm{~h}$. Effects of control PON1 and PEP-1 peptide on the cell viability of INS-1 cells treated with cytokines (C). Cells pretreated with $2 \mu \mathrm{M}$ control PON1 or $2 \mu \mathrm{M}$ PEP-1 peptide were incubated with a combination of cytokines for $24 \mathrm{~h}$. Effects of transduced PEP-1-PON1 on the cell viability of INS-1 cells treated with methyl viologen (MV), nitroprusside (SNP), and high glucose (D). Cells pretreated with $2 \mu \mathrm{M}$ PEP-1-PON1 were incubated with $0.2 \mathrm{mM} \mathrm{MV}, 0.2$ $\mathrm{mM}$ SNP, and $40 \mathrm{mM}$ glucose for $24 \mathrm{~h}$. Bars in the figures represent the mean \pm SEM obtained from 4-8 independent experiments. $* * * \mathrm{P}<0.001$, compared to the untreated control group, and ${ }^{\#} \mathrm{P}<0.05,{ }^{\# \#} \mathrm{P}<0.01$, and ${ }^{\# \# \# P} \mathrm{P}<0.001$, compared to the cytokine-, MV-, SNP-, or glucose-treated group. 
PEP-1-PON1 into INS-1 cells could be evidently confirmed by immunofluorescence analysis. As shown in Fig. 1C, PEP-1PON1-binding fluorescence was uniformly distributed in the cytoplasm, but no fluorescence signal was observed in the control PON1-treated cells. Transduced PEP-1-PON1 in INS-1 cells remained stable until $24 \mathrm{~h}$ after treatment, subsequently decomposing over time (Fig. 1D). These results indicated that the PEP-1-PON1 was rapidly delivered to INS-1 cells, uniformly distributed throughout the cytoplasm, and maintained in the cells for at least $24 \mathrm{~h}$. Therefore, PEP-1-mediated PON1 transduction appears to be an effective method for extrinsic supplementation of PON1 proteins in beta cells.

\section{Effect of transduced PEP-1-PON1 on cell viability in cytokine-treated cells}

The biological efficacy of transduced PEP-1-PON1 was assessed by measuring the viability of cytokine-treated INS-1 cells. In the pancreas of patients with autoimmune diabetes, infiltrated macrophages and $\mathrm{T}$ cells locally secrete several proinflammatory cytokines, which might work together, leading to the destruction of beta cells (1). Thus, in this study, the cytoprotective effects of transduced PEP-1-PON1 were observed in INS-1 cells treated with a combination of three typical proinflammatory cytokines (IL-1 $\beta, \mathrm{TNF}-\alpha$, and IFN- $\gamma$ ). As shown in Fig. 2A, the treatment of INS-1 cells with different concentrations of cytokine mixtures induced cell death in a dose-dependent manner. Approximately half of the total cells were destroyed after $24 \mathrm{~h}$-long exposure to a combination of $25 \mathrm{pM}$ IL-1 $\beta, 125$ pM TNF- $\alpha$, and 125 pM IFN- $\gamma$. However, pretreatment of PEP-1-PON1 gradually increased cell viability in cytokine-treated cells in a dose-dependent manner (Fig. 2B). In contrast, neither control PON1 lacking PEP-1 nor PEP-1 lacking PON1 had a significant effect on the survival rate of cytokine-treated cells (Fig. 2C). We also tested whether the transduced PEP-1-PON1 could protect cells from the deleterious effects of other cytotoxic agents such as methyl viologen (MV), sodium nitroprusside (SNP), and high glucose. These agents are known to increase the intracellular levels of ROS or NO, which are important mediators of beta cell destruction in autoimmune diabetes $(2,3)$. As shown in Fig. 2D, pretreatment of INS-1 cells with $2 \mu \mathrm{M}$ PEP-1-PON1 exerted significant protective effect from the destruction induced by $0.2 \mathrm{mM} \mathrm{MV}, 0.2 \mathrm{mM} \mathrm{SNP}$, and $40 \mathrm{mM}$ glucose, respectively.

\section{Effects of transduced PEP-1-PON1 on cytokine-induced ROS and NO production}

We investigated whether PEP-1-PON1 plays a role in cytoprotection by lowering the levels of ROS and $\mathrm{NO}$ in cytokine-treated cells. As shown in Fig. 3A and 3B, cytokine treatment induced a marked increase in the ROS and $\mathrm{NO}$ levels by 5.6- and 7.1-folds, respectively. However, this cytokine-induced increase in ROS and NO levels was significantly suppressed by pretreatment of PEP-1-PON1.
Biological macromolecules, including DNA, proteins, and lipids, are susceptible to damage by oxygen radicals and NO attack. In this study, DNA fragmentation was found to be extensively induced in INS-1 cells on treatment with a combination of cytokines for $24 \mathrm{~h}$. Surprisingly, the DNA damage induced by cytokines was almost completely blocked by pretreatment with $2 \mu \mathrm{M}$ PEP-1-PON1 for $1 \mathrm{~h}$ (Fig. 3C). Thus, these results indicated that transduced PEP-1-PON1 exerted cytoprotective effects by lowering the levels of ROS and NO in cytokine-treated INS-1 cells.

\section{Effect of transduced PEP-1-PON1 on insulin secretion in cytokine-treated cells}

Proinflammatory cytokines have been reported to inhibit insulin secretion by reducing the ATP/ADP ratio because of
A

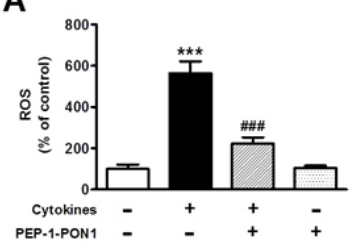

C

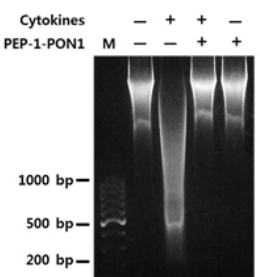

B
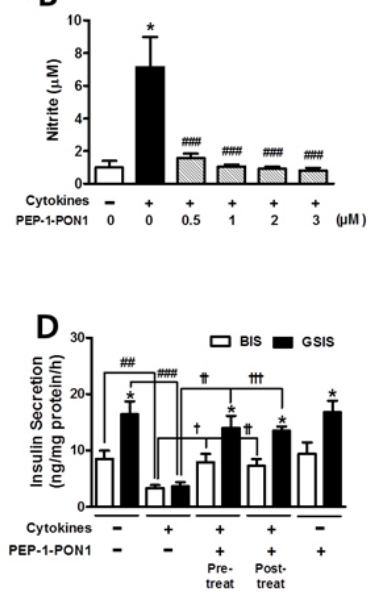

Fig. 3. Effects of transduced PEP-1-PON1 on the ROS and nitrite levels in cytokine-treated INS-1 cells (A, B). Cells pretreated with $2 \mu \mathrm{M}$ PEP-1-PON1 were incubated with a combination of cytokines for $24 \mathrm{~h}$. Effect of transduced PEP-1-PON1 on cytokine-induced DNA fragmentation (C). INS-1 cells pretreated with $2 \mu \mathrm{M}$ PEP-1-PON1 were incubated with a combination of cytokines for $24 \mathrm{~h}$. Total DNA extracted from the cells was separated on $1.2 \%$ agarose gel. M; 100-bp DNA ladder marker. Effect of transduced PEP-1-PON1 on insulin secretion in cytokine-treated INS-1 cells (D). In the pretreated group, cells pretreated with $2 \mu \mathrm{M}$ PEP-1-PON1 were incubated with a combination of cytokines in $\mathrm{KRBH}$ buffer at $37^{\circ} \mathrm{C}$ for $1 \mathrm{~h}$. In post-treated group, the cells were treated with a combination of cytokines for $1 \mathrm{~h}$, and subsequently treated with $2 \mu \mathrm{M}$ PEP-1-PON1 in KRBH buffer at $37^{\circ} \mathrm{C}$ for $1 \mathrm{~h}$. BIS; basal insulin secretion, GSIS; glucose-stimulated insulin secretion. Insulin secretion from the cells was quantified using an insulin ELISA kit and adjusted by the cellular protein content. Bars in the figures represent the mean \pm SEM obtained from 5-8 independent experiments. ${ }^{* P}<0.05$ and $* * * P<0.001$, compared to the untreated control group or the corresponding BIS group, and $\#$ \# $\mathrm{P}<0.01$ and \#\#\#P $<0.001$, compared to the cytokine-treated group, and ${ }^{\top} \mathrm{P}<0.05$, ${ }^{+}{ }_{\mathrm{P}}<0.01$, and ${ }^{+}{ }^{+} \mathrm{P}<0.001$, compared to the cytokine-treated group. 
mitochondrial dysfunction induced by $\mathrm{NO}$ overproduction in the INS-1 cells $(17,18)$. Therefore, we investigated whether transduced PEP-1-PON1 contributes to the recovery of impaired secretory function of INS-1 cells. As shown in Fig. 3D, the control cells secreted $8.5 \mathrm{ng}$ insulin $\cdot \mathrm{mg}$ protein $^{-1} \cdot \mathrm{h}^{-1}$ under basal conditions and secreted $16.4 \mathrm{ng}$ insulin $\cdot \mathrm{mg}$ protein $^{-1} \cdot \mathrm{h}^{-1}$ under glucose-stimulated conditions. Basal insulin secretion (BIS) and glucose-stimulated insulin secretion (GSIS) were induced by 3 and $25 \mathrm{mM}$ glucose, respectively. Cytokine treatment of cells for $1 \mathrm{~h}$ resulted in significant decrease in insulin secretion by $\sim 4 \mathrm{ng}$ insulin $\cdot \mathrm{mg}$ protein ${ }^{-1} \cdot \mathrm{h}^{-1}$ under both BIS and GSIS conditions, leading to a serious defect in the insulin secretory function. However, the decrease in insulin secretion by cytokines was restored to a level similar to that of control cells after pretreatment with $2 \mu \mathrm{M}$ PEP-1-PON1 for $1 \mathrm{~h}$, which indicated that PEP-1-PON1 exerts a beneficial effect of restoring the impaired insulin secretory function of INS-1 cells. On the other hand, no significant difference was noted between pretreated and post-treated PEP-1-PON1 in the ability to restore impaired insulin secretion (Fig. 3D). Although detailed mechanisms have to be elucidated, the reduction of intracellular NO level by transduced PEP-1-PON1 might certainly contribute to the recovery of impaired insulin secretion in cytokine-treated INS-1 cells.

\section{Effects of transduced PEP-1-PON1 on the levels of inflammatory mediators, ER stress proteins, and apoptosis-related proteins}

Excessive ROS stimulates redox-sensitive signal transduction through mitogen-activated protein kinases, activator protein-1, and NFKB, which then induce the expression of proinflammatory cytokines, inflammatory mediators, and chemotactic agents involved in local immune response. Thus, this redox-sensitive signaling results in cyclic amplification of ROS and ultimately leads to cellular dysfunction and destruction of beta cells $(2,19)$. In this study, western blotting showed that the level of inflammatory mediators (iNOS and COX-2) was markedly increased by cytokines, as previously reported (20). However, cytokine-induced upregulation of iNOS and COX-2 was inhibited by pretreatment of $2 \mu \mathrm{M}$ PEP-1-PON1 for $1 \mathrm{~h}$ (Fig. 4A). These results indicated that transduced PEP-1-PON1 inhibits inflammatory response by lowering the expression of inflammatory mediators and prevents cyclic amplification of ROS in cytokine-treated beta cells.

Proinflammatory cytokines induce ER stress through NO-mediated depletion of ER calcium in beta cells (21). Activation of ER stress signaling cascades leads to translational attenuation of global proteins, while facilitating the formation of transcription factors such as ATF-4, ATF-6, and XBP-1. These transcriptional factors bind to the nuclear promoters to upregulate ER stress proteins such as CHOP and ER chaperones (21-23). In this study, we confirmed cytokineinduced upregulation of ATF-4, spliced XBP-1, and CHOP at the protein level by western blotting. However, PEP-1-PON1 transduction reduced the expression of these ER stress proteins induced by cytokines (Fig. 4B). Because transduced PEP-1-PON1 markedly reduced the NO levels induced by cytokines (Fig. 3B), PEP-1-PON1 might inhibit the induction of ER stress by preventing NO-mediated depletion of ER calcium in cytokine-treated INS-1 cells. Under prolonged ER stress, the cells are committed to apoptosis. Studies have shown that ER stress-mediated apoptosis is regulated by several signaling molecules, including JNK, CHOP, and caspases (22-24). JNK is activated by inositol-requiring protein $1 \alpha$ during cytokineinduced ER stress, which contributes to the apoptosis of beta cells $(24,25)$. As shown in Fig. 4B, it was confirmed that cytokine-induced activation of JNK was markedly inhibited by PEP-1-PON1 transduction. CHOP is a pro-apoptotic protein that is upregulated by the transcriptional factor ATF-4 and is uniquely responsive to $\mathrm{ER}$ stress. It has been reported that CHOP contributes to ER stress-mediated beta cell apoptosis by promoting the degradation of the anti-apoptotic proteins Bcl-2 and $\mathrm{Mcl}-1$, leading to cytochrome $\mathrm{c}$ release and caspase-3 activation $(21,23,24)$.

Consistent with previous studies $(3,4)$, it was again confirmed that cytokine treatment of INS-1 cells resulted in an increase in the level of pro-apoptotic proteins, while the level of anti-apoptotic proteins was suppressed (Fig. 4C). This reciprocal change in the levels of pro-apoptotic and anti-apoptotic proteins by cytokines was restored by
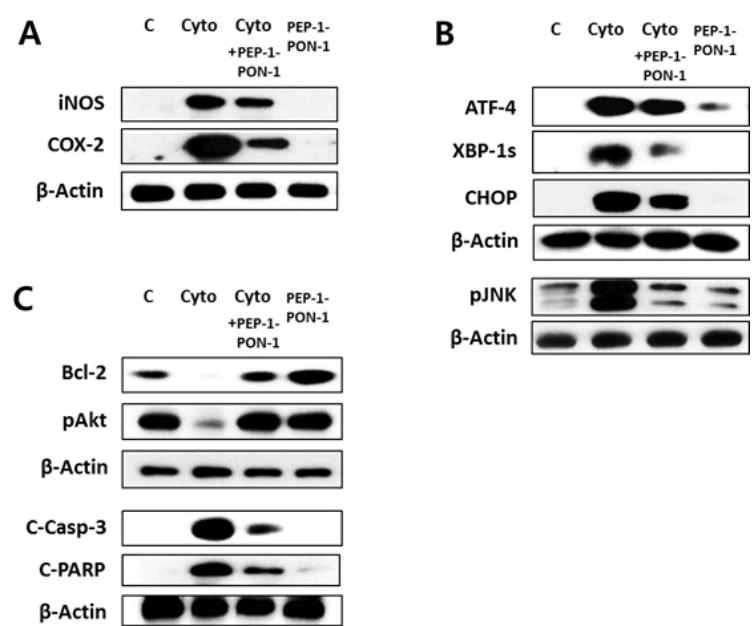

Fig. 4. Effects of transduced PEP-1-PON1 on the levels of inflammatory mediators, ER stress proteins, and apoptosis-related proteins in cytokine-treated INS-1 cells. Cells pretreated with 2 $\mu \mathrm{M}$ PEP-1-PON1 were incubated with a combination of cytokines for $24 \mathrm{~h}$. The levels of inflammatory mediators (iNOS and COX-2) (A), ER stress proteins (ATF-4, XBP-1s, CHOP, pJNK) (B), and apoptosis-related proteins (Bcl-2, pAkt, C-Casp-3, C-PARP) (C) were determined by western blotting. C-Casp-3; cleaved caspase-3, C-PARP; cleaved poly (ADP-ribose) polymerase. 
PEP-1-PON1. Pretreatment of $2 \mu \mathrm{M}$ PEP-1-PON1 for $1 \mathrm{~h}$ in cytokine-treated cells restored the levels of anti-apoptotic and cell survival proteins (Bcl-2 and Akt), while it suppressed the levels of pro-apoptotic proteins (cleaved caspase-3 and cleaved PARP). These results suggested that inhibition of the pro-apoptotic pathway is closely associated with the ability of PEP-1-PON1 to prevent cytokine-induced cell destruction.

In conclusion, PEP-1-PON1 played a beneficial role in preventing cell destruction and restoring insulin secretion by alleviating the oxidative/nitrosative stress, inflammation, and ER stress in cytokine-treated INS-1 cells.

\section{MATERIALS AND METHODS}

\section{Materials}

The cell-permeable fusion protein PEP-1-PON1 was expressed and purified as previously described (26). A schematic representation of the expression vector for PEP-1-PON1 and the expressed fusion protein is shown in Fig. 1A. Rat IL-1 $\beta$, TNF- $\alpha$, and IFN- $\gamma$ were obtained from $R$ \& D Systems (Minneapolis, MN, USA), Enzo (Farmingdale, NY, USA), and Chemicon (Billerica, MA, USA), respectively. Total ROS detection kit was obtained from Enzo (Plymouth Meeting, PA, USA). Rat insulin ELISA kit was purchased from Alpco (Salem, $\mathrm{NH}$, USA). Alexa Fluor 488 secondary antibody and apoptotic DNA ladder detection kit were obtained from Invitrogen (Frederick, MD, USA). Most of the antibodies used in western blotting were purchased from Cell Signaling Technology (Danvers, MA, USA).

\section{Transduction of PEP-1-PON1 into INS-1 cells}

INS-1 rat insulinoma cells were maintained in complete RPMI-1640 medium containing 10\% fetal bovine serum (FBS), $100 \mu \mathrm{g} / \mathrm{ml}$ streptomycin, $100 \mathrm{U} / \mathrm{ml}$ penicillin, and $250 \mathrm{ng} / \mathrm{ml}$ amphotericin $\mathrm{B}$ at $37^{\circ} \mathrm{C}$. For dose-dependent transduction of PEP-1-PON1, the INS-1 cells were grown to confluence in 6 -well plates for $24 \mathrm{~h}$. These cells were then starved for $6 \mathrm{~h}$ in the FBS-free culture medium and treated with different concentrations of PEP-1-PON1 for $1 \mathrm{~h}$. For time-dependent transduction, the cells were treated with $2 \mu \mathrm{M}$ PEP-1-PON1 for 1-120 min. To determine the intracellular stability of the transduced PEP-1-PON1, the cells were treated with $2 \mu \mathrm{M}$ PEP-1-PON1 for $1 \mathrm{~h}$ and washed with fresh medium to remove fusion proteins that were not transduced into cells. The cells were further incubated for 6-48 $\mathrm{h}$.

\section{Cell viability analysis}

Cell viability was estimated with a colorimetric assay using 3-[4,5-dimethylthiazol-2-yl]-2,5-diphenyltetrazolium bromide (MTT).

\section{Western blotting and immunofluorescence analysis}

Western blotting was performed as previously described (15). To confirm the intracellular localization of transduced
PEP-1-PON1, cells pretreated with $2 \mu \mathrm{M}$ PEP-1-PON1 were fixed with $4 \%$ paraformaldehyde. These cells were treated with rabbit anti-His-tag polyclonal antibody (Sigma-Aldrich, St. Louis, MO, USA) at the dilution of 1:1000 for $2 \mathrm{~h}$ and incubated with Alexafluor 488-conjugated goat anti-rabbit IgG antibody (Invitrogen, Carlsbad, CA, USA) at the dilution of 1:2000 in the dark for $1 \mathrm{~h}$ at room temperature. 4'6Diamidino-2-phenylindole (DAPI) staining was simultaneously performed to identify the nuclei.

\section{Measurement of DNA fragmentation}

DNA fragmentation was measured using an apoptotic DNA ladder detection kit. Cells pretreated with $2 \mu \mathrm{M}$ PEP-1-PON1 were incubated with a combination of cytokines ( 25 pM IL-1 $\beta$, $125 \mathrm{pM}$ TNF- $\alpha$, and $125 \mathrm{pM}$ IFN- $\gamma$ ) for $24 \mathrm{~h}$. The total DNA was extracted and then separated on $1.2 \%$ agarose gel containing ethidium bromide.

\section{Measurement of ROS and nitrite levels}

Intracellular ROS level was estimated by measuring ROS-induced fluorescence using an ROS detection kit as previously described (15). To determine NO production by the cells, the concentration of nitrite, a stable oxidative metabolite of NO, was measured as previously described (27).

\section{Measurement of insulin secretion}

INS-1 cells were incubated in HEPES-buffered Krebs-Ringer bicarbonate (KRBH buffer) $(128.8 \mathrm{mM} \mathrm{NaCl}, 4.8 \mathrm{mM} \mathrm{KCl}, 1.2$ $\mathrm{mM} \mathrm{KH_{2 }} \mathrm{PO}_{4}, 1.2 \mathrm{mM} \mathrm{MgSO}_{4}, 2.5 \mathrm{mM} \mathrm{CaCl}, 5 \mathrm{mM}$ $\mathrm{NaHCO}_{3}$, and $10 \mathrm{mM}$ HEPES, $\mathrm{pH}$ 7.4) containing $3 \mathrm{mM}$ glucose for $30 \mathrm{~min}$ at $37^{\circ} \mathrm{C}$. The solution was replaced with fresh $\mathrm{KRBH}$ buffer containing 3 or $25 \mathrm{mM}$ glucose, pretreated with $2 \mu \mathrm{M}$ PEP-1-PON1 for $1 \mathrm{~h}$, and further incubated with a combination of cytokines (25 pM IL-1 $\beta, 125$ pM TNF- $\alpha$, and $125 \mathrm{pM}$ IFN- $\gamma$ ) for $1 \mathrm{~h}$. To determine whether there was a difference between pretreatment and post-treatment of PEP-1-PON1, the cytokines were first added to the culture medium for $1 \mathrm{~h}$ in other cell groups, and then $2 \mu \mathrm{M}$ PEP-1-PON1 was post-treated for $1 \mathrm{~h}$.

\section{ACKNOWLEDGEMENTS}

This research was supported by Basic Science Research Program through the National Research Foundation of Korea (NRF) founded by the Ministry of Education [2016R1D1A 3B03932554].

\section{CONFLICTS OF INTEREST}

The authors have no conflicting interests.

\section{REFERENCES}

1. Eizirik DL and Mandrup-Poulsen TA (2001) A choice of 
death: the signal-transduction of immune-mediated beta-cell apoptosis. Diabetologia 44, 2115-2133

2. Padgett LE, Broniowska KA, Hansen PA, Corbett JA and Tse HM (2013) The role of reactive oxygen species and proinflammatory cytokines in type 1 diabetes pathogenesis. Ann NY Acad Sci 1281, 16-35

3. Størling J, Binzer J, Andersson AK et al (2005) Nitric oxide contributes to cytokine-induced apoptosis in pancreatic beta-cells via potentiation of JNK activity and inhibition of Akt. Diabetologia 48, 2039-2050

4. Grunnet LG, Aikin R, Tonnesen MF et al (2009) Proinflammatory cytokines activate the intrinsic apoptotic pathway in beta-cells. Diabetes 58, 1807-1815

5. Hayek T, Hussein K, Aviram M et al (2005) Macrophage foam-cell formation in streptozotocin-induced diabetic mice: stimulatory effect of glucose. Atherosclerosis 183, 25-33

6. Ahmed FN, Naqvi FN and Shafiq F (2006) Lipid peroxidation and serum antioxidant enzymes in patients with type 2 diabetes mellitus. Ann NY Acad Sci 1084, 481-489

7. Kulka M (2016) A review of paraoxonase 1 properties and diagnostic applications. Pol J Vet Sci 19, 225-232

8. Mackness M and Mackness B (2015) Human paraoxonase-1 (PON1): Gene structure and expression, promiscuous activities and multiple physiological roles. Gene 567, 12-21

9. Rozenberg O, Shiner M, Aviram M and Hayek T (2008) Paraoxonase 1 (PON1) attenuates diabetes development in mice through its antioxidative properties. Free Radic Biol Med 44, 1951-1959

10. Koren-Gluzer M, Aviram M, Meilin E and Hayek T (2011) The antioxidant HDL-associated Paraoxonase 1 (PON1) attenuates diabetes development and stimulates $\beta$-cell insulin release. Atherosclerosis 219, 510-518

11. Kota SK, Meher LK, Kota SK, Jammula S, Krishna SV and Modi KD (2013) Implications of serum paraoxonase activity in obesity, diabetes mellitus, and dyslipidemia. Indian J Endocrinol Metab 17, 402-412

12. Lortz S, Tiedge M, Nachtwey T, Karlsen AE, Nerup J and Lenzen S (2000) Protection of insulin-producing RINm5F cells against cytokine-mediated toxicity through overexpression of antioxidant enzymes. Diabetes 49, 1123-1130

13. Eum WS, Choung IS, Li MZ et al (2004) HIV-1 Tat-mediated protein transduction of $\mathrm{Cu}, \mathrm{Zn}$-superoxide dismutase into pancreatic $\beta$-cells in vitro and in vivo. Free Radic Biol Med 37, 339-349

14. Snyder EL and Dowdy SF (2005) Recent advances in the use of protein transduction domains for the delivery of peptides, proteins and nucleic acids in vivo. Expert Opin
Drug Deliv 2, 43-51

15. Lee SJ, Kang HK, Eum WS, Park J, Choi SY and Kwon HY (2017) Tat-biliverdin reductase A protects INS-1 cells from human islet amyloid polypeptide-induced cytotoxicity by alleviating oxidative stress and ER stress. Cell Biol Int 41, 514-524

16. Lenzen S, Drinkgern J and Tiedge M (1996) Low antioxidant enzyme gene expression in pancreatic islets compared with various other mouse tissues. Free Radic Biol Med 20, 463-466

17. Meredith M, Rabaglia ME, Corbett JA and Metz SA (1996) Dual functional effects of interleukin-1beta on purine nucleotides and insulin secretion in rat islets and INS-1 cells. Diabetes 45, 1783-1791

18. Chen M, Yang Z, Wu R and Nadler JL (2002) Lisofylline, a novel anti-inflammatory agent, protects pancreatic $\beta$-cells from proinflammatory cytokine damage by promoting mitochondrial metabolism. Endocrinology 143, 2341-2348

19. Ho E and Bray TM (1999) Antioxidant, NFkappaB activation, and diabetogenesis, Proc Soc Exp Biol 222, 205-213

20. Corbett JA, Kwon G, Marino MH et al (1996) Tyrosine kinase inhibitors prevent cytokine-induced expression of iNOS and COX-2 by human islets. Am J Physiol 270, C1581-C1587

21. Eizirik DL, Cardozo AK and Cnop M (2008) The role for endoplasmic reticulum stress in diabetes mellitus. Endo Rev 29, 42-61

22. Xu C, Bailly-Maitre B and Reed JC (2005) Endoplasmic reticulum stress: cell life and death decisions. J Clin Invest 115, 2656-2664

23. Brozzi F and Eizirik DL (2016) ER stress and the decline and fall of pancreatic beta cells in type 1 diabetes. Ups J Med Sci 121, 133-139

24. Zhang K and Raufman RJ (2008) Identification and characterization of endoplasmic reticulum stress-induced apoptosis in vivo. Methods Enzymol 442, 395-419

25. Urano F, Wang X, Bertolotti A et al (2000) Coupling of stress in the ER to activation of JNK protein kinases by transmembrane protein kinase IRE1. Science 287, 664-666

26. Kim MJ, Jeong HJ, Kim DW et al (2014) PEP-1-PON1 protein regulates inflammatory response in Raw 264.7 macrophages and ameliorates inflammation in a TPA-induced animal model. PLoS ONE 9, e86034

27. Misko TP, Schilling RJ, Salvemini D, Moore WM and Currie MG (1993) A fluorometric assay for the measurement of nitrite in biological samples. Anal Biochem 214, 11-16 